\title{
ALGUNS ASPECTOS EPIDEMIOLOGICOS DA MORTALIDADE POR ACIDENTES DE TRÂNSITO DE VEICULO A MOTOR NA CIDADE DE SÃo PAULO, BRASIL
}

\author{
Ruy LAURENTI* \\ Maria Ap. T. GUERRA ** \\ Regina Ap. BASEOTTO ** \\ Maria T. KLINCERVICIUS **
}

\section{RSPSP-147}

LAURENTI, R. et al. - Alguns aspectos epidemiológicos da mortalidade por acidentes de trânsito de veiculo a motor na Cidade de São Paulo, Brasil. Rev. Saúde públ., S. Paulo, 6: 329-41, 1972.

REsumo: Foram estudadas algumas caracteristicas dos bbitos por acidentes de trânsito de veículos a motor, no municipio de São Paulo, ocorridos entre $10^{\circ}$ de janeiro a 31 de dezembro de 1970. Todas as caracteristicas do falecido e do acidente foram coletadas a partir dos dados registrados nos laudos de necrópsias existentes no Instituto Médico Legal. O estudo evidenciou que a mortalidade por acidentes de veículo a motor é alta, maior no sexo masculino, aumenta com a idade, sendo que o maior coeficiente foi para maiores de 60 anos. A zona da cidade com maior número de acidentes é a zona Sul, existindo áreas (distritos policiais) $e$ vias públicas preferenciais quanto a ocorrência, em todas as 4 zonas do municipio; a maior ocorrência de acidentes foi aos sábados e domingos; os pedestres compreendem a grande maioria dos falecidos; proporçấo aprecível dos falecidos recebeu atendimento hospitalar apos o acidente. Foram relacionados também o número total de acidentes, vitimas e mortes mostrando que para cada 100 acidentes ocorreram 62,50 vitimas e 5,13 mortes, e para cada 100 vitimas, 18,22 mortes.

UnITERMos: Acidentes de transito *; Veiculos a motor *; Mortalidade *; Epidemiologia.
INTRO D U G A O

Em todo o mundo, os acidentes de trânsito, e em especial aqueles causados por veículos a motor, vem assumindo destaques cada vez maior como causa de morte, sendo que, em inúmeros países, quanto a magnitude, a mortalidade por essa causa figura entre as primeiras. O fato de incidirem principalmente sobre os jovens e os adultos jovens tem sido destacado para chamar a atenção quanto à necessidade de, contra eles, serem tomadas medidas preventivas eficazes. A primeira morte, por essa causa nos Estados Unidos, ocorreu em 1899 e a intensidade do problema foi tal que em 1951 foi ali registrado o milionésimo caso; por outro lado, sabe-se que atualmente, em todo o mundo, morrem mais de cem mil pessoas por acidentes de veículo a motor 7 .

Já há muitos anos, em inúmeros países, a mortalidade por acidentes de veículo a motor ultrapassou aquela consequiente a outras causas ou grupo de causas, como por exemplo, as doenças infecciosas. Até mesmo em áreas ou países em desenvolvimento, esses acidentes tem sido motivo de preocupação, visto que os mesmos vêm aumentando progressivamente. Na Nigéria, um estudo

* Do Departamento de Epidemiologia da Faculdade Je Saúde Pública da USP - Av. Dr. Arnaldo, 715 - Sao Paulo, S.P., Brasil.

* Tcademicas de Medicina do Departamento de Medicina Preventiva da Faculdade de Medicina da USP - Av. Dr. Arnaldo, 455 - São Paulo, S.P., Brasil." 
LAURENTI, R. et al. - Alguns aspectos epidemiológicos da mortalidade por acidentes de transito de veículo a motor na cidade de São Paulo, Brasıl. Rev. Saúde públ., S. Paulo, 6: $329-41,1972$.

sobre acidente na infância ${ }^{\circ}$ evidenciou que aqueles causados por veículos a motor são ali vinte vezes mais perigosos que os mesmos considerados nos Estados Unidos e dez vezes mais que na Inglaterra. FÁvero ${ }^{3}$ estudando a epidemiologia dos acidentes de trânsito em Ribeirão Preto refere que os mesmos, pelo número de pessoas lesadas e de óbitos que provocam, constituem sério problema de saúde. $O$ autor, além de seus próprios dados, reporta-se a uma pesquisa da Repartição Sanitária Panamericana, mostrando que em Ribeirão Preto, nos anos de 1962 e 1963, na mortalidade de indivíduos entre 15 e 74 anos, os acidentes de trânsito mataram mais do que a diabetes mellitus, que a broncopneumo- nia e quase tanto quanto a tuberculose pulmonar.

Na cidade de Sāo Paulo, em 1950, o risco de morrer por acidente de veículo a motor foi aproximadamente cinco vezes menor do que o devido à tuberculose (respectivamente 12,2 e 60,0/100.000 habitantes) e em 1967, os acidentes mataram cerca de 1,4 vezes mais do que a tuberculose (respectivamente 24,2 e 17,3/100.000 habitantes). De 1950 para 1960 os níveis ce mortalidade causada por esse tipo de acidente permaneceram mais ou menos estacionários. A partir da década de 60 , porém, a mortalidade aumentou bastante, atingindo em 1970, valor que representa quase que o dobro do verificado em 1960. (Tabela 1).

TA E E L A 1

Mortalidade por Acidente de veículo a motor no Município de S. Paulo - Anos 1950 - 1970 (Coef. X 100.000 habs.)

\begin{tabular}{c|c|c|c}
\hline Ano & Coeficiente & Ano & Coeficiente \\
\hline $19: 50$ & 12,2 & 1960 & 13,6 \\
51 & 12,2 & 61 & 17,8 \\
52 & 12,5 & 62 & 18,3 \\
53 & 15,3 & 63 & 20,4 \\
54 & 16,1 & 64 & 22,6 \\
55 & 14,2 & 65 & 18,2 \\
56 & 12,6 & 66 & 23,1 \\
57 & 12,5 & 67 & 25,2 \\
58 & 13,5 & 68 & $\ldots$ \\
59 & 14,1 & 69 & 22,4 * \\
\hline
\end{tabular}

" Coeficiente corrigido somente para residentes.

Fonte: Dados coletados no Depto. de Estatística - Secretaria de Planejamento, São Paulo.

A mortalidade pela causa aqui considerada atingiu, nos últimos anos para os quais se dispõe de dados, os mesmos niveis observados em países desenvolvidos. Assim, por exemplo, em anos próximos a 1968 ela foi de 26,4/100.000 habitantes no Canadá, 22,4 na Dinamarca, 21,4 na Itália, 22,2 na Holanda, 31,6 no Luxemburgo e 24,5 na Suissa 1.

A gravidade que vem assumindo o pro- blema em São Paulo foi o motivo deste estudo, do ponto de vista de sua epidemiologia. Inicialmente, pensou-se em uma análise mais ampla a respeito do mesmo, a partir dos "Boletins de Ocorrência" feitos pelas autoridades policiais. Como se sabe, entre nós, praticamente todos os acidentes de veículo a motor, e principalmente aqueles que ocasionam lesōes em pedestres ou ocupantes dos 
LAURENTI, R. et al. - Alguns aspectos epidemiológicos da mortalidade por acidentes de trânsito de veículo a motor na cidade de São Paulo, Brasıl. Rev. Saúde públ., S. Paulo, 6: $329-41,1972$.

veículos, tem sua ocorrência registrada pela autoridade policial da circunscrição (distrito policial) em que aconteceu 0 acidente. Esse registro é feito no chamado "Boletim de Ocorrência", o qual contem dados extremamente valiosos para um estudo epidemiológico bem detalhado, pois são anotadas informações como: local e tipo de acidente, tipo de veículo, número e características das vítimas, além de outras tais como tipo de infração, licença para đirigir, residência das pessoas envolvidas, procedência do veículo (se de São Paulo ou de fora).

Um estudo desse tipo justificava-se plenamente, pois poderiam ser obtidas informações várias tendo-se em vista uma programação que visasse à prevenção dos acidentes. O que se objetivava era analisar os acidentes, as vítimas (pessoas lesadas) e as mortes, segundo várias características. Assim, por exemplo, alguns dados oficiais divulgados pelas autoridades responsáveis pelo trânsito, informam, entre outros, índices e coeficientes de feridos e mortos por habitantes e o mesmo por veículos; sabe-se, porém, que muitas pessoas feridas ou mortas não são residentes em São Paulo, e como não é feita a correção necessária, o risco de morrer da população fica superestimado, da mesma forma que a morbidade e a letalidade não são medidas corretamente. Isso não tem apenas valor epidemiológico descritivo teórico, mas do ponto de vista prático poderia dar uma contribuição importante visando a medidas preventivas, desde que as características dos acidentes e das vítimas fossem analisadas com mais rigor.

Dadas algumas dificuldades surgidas para a tabulação e análise dos "Boletins de Ocorrência", o estudo limitou-se apenas às mortes. A maneira mais simples seria a análise dos atestados de óbito que, por si mesmos, poderiam dar informações importantes. Ocorre, porém, que todos os casos de óbitos decorrentes de causas violentas ou acidentes são submetidos à necrópsia no Instituto Médico Legal e esse órgão não utiliza o modelo internacional do atestado de óbito. Desconhece-se, portanto, a causa básica, ou seja, no caso, as circunstâncias do acidente. Os atestados de óbito fornecidos pelo Instituto Médico Legal só apresentam a causa externa da lesão, - que torna impossível um estudo como o proposto. Levando-se em conta o fato de que todos os óbitos por acidente são necropsiados, mesmo aqueles em que as vítimas tenham falecido em hospitais aos quais foram encaminhadas após a ocorrência, uma boa maneira de estudar o problema seria através dos laudos de necrópsias. Deve ser acrescentado que as mesmas são solicitadas pelas autoridades policiais e que na requisiçã̃o constam vários itens de importância para a caracterização das vítimas e do acidente.

Sendo então possível o estudo deste material, juntamente com algumas informações coletadas no Departamento Estadual de Trânsito (DETRAN), foi proposta esta análise epidemiológica descritiva dos óbitos causados por acidentes de veículos a motor na cidade de São Paulo.

\section{MATERIAL E METODOS}

Para acidentes de trânsito de veículo a motor foi adotado o conceito da Classificação Internacional de Doenças (8." Revisão - 1965), segundo a qual é "qualquer acidente com veículo a motor ocorrido na via pública. considerado como ocorrido na via pública se houver sucedido inteiramente, originado ou terminado nela ou se houver atingido um veículo situado parcialmente na via pública. $O$ acidente é considerado de via pública se não for especificado outro lugar".

Serão analisados nesta apresentação somente os acidentes causados por veí- 
LAURENTI, $R$. et al. - Alguns aspectos epidemiológicos da mortalidade por acidentes de transito de veículo a motor na cidade de săo Paulo, Brasil. Rev. Saúde públ., S. Paulo, 6: 329-41, 1972 .

culo a motor tipo automóvel, ônibus ou caminhão, não sendo incluídas motocicletas e bicicletas motorizadas. Assim, quando na apresentação dos resultados for referido "motociclista" ou "ciclista", deverá o fato ser entendido como acidente de automóvel, caminhão ou ônibus com uma motocicleta ou bicicleta motorizada ou não.

Para o estudo proposto foram revistos todos os laudos de necrópsia do Instituto Médico Legal referentes a mortes por acidentes ocorridos de $10^{\circ}$ de janeiro a 31 de dezembro de 1970; aqueles referentes a acidentes de veículos a motor foram separados, não se incluındo na análise aqueles cujo local de ocorrência tivesse sido fora da cidade de São Paulo. (O Instituto realiza necrópsias de mortes violentas ocorridas em alguns municípios vizinhos, que não dispõem de serviço médico legal). Para aqueles casos em que o acidente ocorreu no município de São Paulo foram anotados: dia da semana, mês, zona da cidade a distrito policial da ocorrência, se a vítima recobeu atenção médica (isto é, se houve hospitalização), qualidade da vítima (pedestre, motorista, passageiro, etc.), e o fato de ser ou não residente em São Paulo.

As informaçóes sobre o total de acidentes de veículo a motor ocorridos na cidade, e não só aqueles que causaram mortes, assim como alguns outros dados pertinentes, foram coletados no DETRAN.

\section{RE SULT A D O S}

Foram realizadas 1883 necrópsias referentes a mortes causadas por veículos a motor, das quais 1746 ocorreram no município de São Paulo. A análise refere-se a estes 1746 casos.

Quanto ao local dos acidentes, segundo as zonas da cidade $e$ os respectivos distritos policiais, pode-se observar na
Tabela 2 que a maior proporção de acidentes ocorreu na zona sul $(32,86 \%)$, vindo a seguir a zona leste $(22,49 \%)$. Quanto às áreas correspondentes aos distritos policiais, o maior número de mortes foi verificado na Cidade Ademar, vindo a seguir São Miguel Paulista, Vila Mangalot, Santo Amaro e Lapa, distritos nos quais se verificaram 25,58\% de todas as mortes. Na Tabela 2, os casos que constam como ignorados são aqueles nos quais a informação não constava no livro de registro do Instituto Médico Legal.

Quanto à distribuição dos óbitos segundo os meses do ano, foi observada uma média de 145 por mês, sendo que o maior número foi verificado em julho $\mathrm{e}$ - menor em fevereiro. Além de julho, os meses de maio, junho, agosto, novembro e dezembro ultrapassaram a média mensal. (Tabela 3).

Os acidentes (fatais ou não), por sua vez, foram mais frequientes em agosto $(10,09 \%)$ e, excluindo-se fevereiro $(6,22 \%)$, que é o mês mais curto, observou-se que julho foi o que teve menor número de acidentes. Comparando-se com o observado para o número de mortes, vemos que julho, com menos acidentes, produziu o maior número de mortes. Na Tabela 3, onde estão expostos esses dados, estão calculados também os riscos de um acidente produzir vitimas (pessoas lesadas), de ocasionar mortes e também o risco de uma vítima de acidente vir a falecer. Como se pode observar, verifica-se que em 1970, na cidade de São Paulo, em média, cada 100 acidentes provocaram 62,5 pessoas feridas e 5,13 mortes. Por outro lado, para cada 100 pessoas feridas, em média, ocorreram 8,22 mortes.

Em relação aos dias da semana verificou-se que, em média, ocorrem 138 mortes por dia da semana no curso do ano, sendo aos sábados e domingos, observados o maior número $(32,43 \%$ 
LAURENTI, R. et al. - Alguns aspectos epidemiológicos da mortalidade por acidentes de trânsito de veículo a motor na cidade de São Paulo, Brasil. Rev. Saúde públ., S. Paulo, 6: 329-41, 1972.

T A B E L A 2

Mortes por acidentes de trânsito de veículo a motor, segundo as zonas da cidade e os distritos policiais de ocorrência dos acidentes - São Paulo - 1970 .

\begin{tabular}{|c|c|c|c|}
\hline Zona & Distrito Policial & n.9 & $\%$ \\
\hline \multirow[t]{2}{*}{ Centro } & $\begin{array}{l}\text { Sé } \\
\text { Bom Retiro } \\
\text { C. Elíseos } \\
\text { Bela Vista } \\
\text { Aclimação } \\
\text { Cambucí } \\
\text { Brás } \\
\text { Parı }\end{array}$ & $\begin{array}{l}47 \\
34 \\
21 \\
32 \\
20 \\
17 \\
46 \\
16\end{array}$ & $\begin{array}{l}3,64 \\
2,63 \\
1,62 \\
2,48 \\
1,55 \\
1,31 \\
3,56 \\
1,24\end{array}$ \\
\hline & Total & 233 & 18,06 \\
\hline \multirow[t]{2}{*}{ Norte } & $\begin{array}{l}\text { Carandirú } \\
\text { C. Verde } \\
\text { V. Maria } \\
\text { Túcuruvi } \\
\text { N. S. do } 6 \\
\text { V. Amália } \\
\text { V. Gustavo } \\
\text { V. S. Maria }\end{array}$ & $\begin{array}{r}21 \\
19 \\
31 \\
19 \\
14 \\
6 \\
37 \\
15\end{array}$ & $\begin{array}{l}1,62 \\
1,47 \\
2,40 \\
1,47 \\
1,08 \\
0,46 \\
2,86 \\
1,16\end{array}$ \\
\hline & Total & 162 & 12,56 \\
\hline \multirow[t]{2}{*}{ Sul } & $\begin{array}{l}\text { S. Amaro } \\
\text { Indianopolis } \\
\text { V. Clementino } \\
\text { Ipiranga } \\
\text { Sacomã } \\
\text { Campo Belo } \\
\text { V. Prudente } \\
\text { V. Guarani } \\
\text { V. Mariana } \\
\text { V. Simão } \\
\text { Parque S. Lucas } \\
\text { C. Ademar }\end{array}$ & $\begin{array}{l}57 \\
40 \\
25 \\
49 \\
43 \\
18 \\
34 \\
11 \\
19 \\
13 \\
36 \\
79\end{array}$ & $\begin{array}{l}4,41 \\
3,10 \\
1,93 \\
3,79 \\
3,33 \\
1,39 \\
2,63 \\
0,85 \\
1,47 \\
1,00 \\
2,79 \\
6,12\end{array}$ \\
\hline & Total & 424 & 32,86 \\
\hline \multirow[t]{2}{*}{ Leste } & $\begin{array}{l}\text { Penha } \\
\text { Alto Moóca } \\
\text { V. Matılde } \\
\text { S. Miguel Paulista } \\
\text { Erm. Matarazzo } \\
\text { Belenzinho } \\
\text { Tatuapé } \\
\text { V. Carrão } \\
\text { Itaquera } \\
\text { V. Rica }\end{array}$ & $\begin{array}{l}33 \\
29 \\
12 \\
74 \\
20 \\
23 \\
24 \\
21 \\
42 \\
12\end{array}$ & $\begin{array}{l}2,55 \\
2,24 \\
0,98 \\
5,73 \\
1,55 \\
1,78 \\
1,86 \\
1,62 \\
3,25 \\
0,93\end{array}$ \\
\hline & Total & 2910 & 22,49 \\
\hline \multirow[t]{2}{*}{ Oeste } & $\begin{array}{l}\text { Lapa } \\
\text { Pinheiros } \\
\text { Perdizes } \\
\text { V. Mangalot } \\
\text { V. Sonia } \\
\end{array}$ & $\begin{array}{l}56 \\
24 \\
13 \\
64 \\
24\end{array}$ & $\begin{array}{l}4,34 \\
1,86 \\
1,00 \\
4,96 \\
1,86\end{array}$ \\
\hline & Total & 181 & 14,08 \\
\hline Total & & 1290 & 100,00 \\
\hline Ignorado & & 456 & \\
\hline Total & & 1746 & \\
\hline
\end{tabular}


LAURENTI, $R$, et al. - Alguns aspectos epidemiológicos da mortalidade por acidentes de transito de refculo a motor na Cidade de Săo Paulo, Brasil. Rev. Saúde públ., S. Paulo, 6: 329-41, 1972.

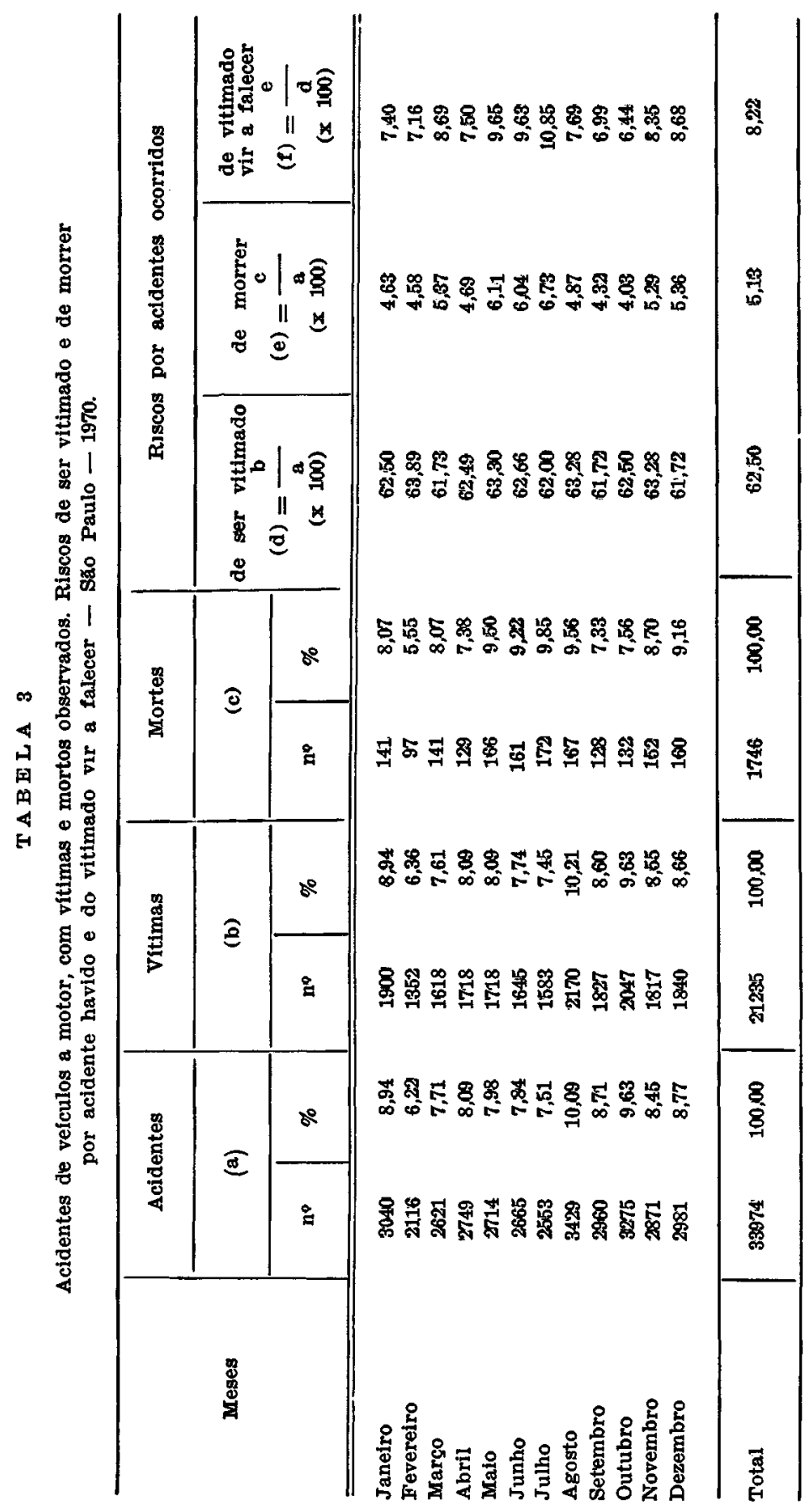


LAURENTI, R. et al. - Alguns aspectos epidemiológicos da mortalliade por acidentes de transito de vefculo a motor na cídade de slo Paulo, Brasil. Rev. Baude publ., S. Paulo, 6: 329-41, 1972.

dos óbitos). Por outro lado, 4." feira é o dia que, em média, verifica-se o menor número, vindo a seguir a 3.a feira (Tabela 4).

TABELA 4

Mortes por acidentes de transito de veiculo a motor, segundo os dias da semana - sto Paulo - 1970

\begin{tabular}{|c|c|c|}
\hline Dia & n? & $\%$ \\
\hline 2." feira & 131 & 13,56 \\
\hline 3.2 telra & 125 & 12,94 \\
\hline 4. feira & 1112 & 11,60 \\
\hline 5. feira & 141 & 14,60 \\
\hline 6. feira & 134 & 13,87 \\
\hline Sábado & 162 & 16,77 \\
\hline Domingo & 161 & 16,66 \\
\hline Total & 966 & 100,00 \\
\hline Ignorado & 780 & \\
\hline Total & 1746 & \\
\hline
\end{tabular}

Os tipos de acidentes de veículo a motor mais frequientes foram as colisões e os atropelamentos, respectivamente $48,27 \%$ e $44,64 \%$. O capotamento é o 3. tipo de acidente mais frequente, porém com uma frequiência bem menor que os anteriormente citados (Tabela 5).

T A B E L A

Acidentes de transito de veicuio a motor segun do o tipo de acidente - sao Paulo - 1970

\begin{tabular}{l|r}
\hline Tipo de sicidente & $\%$ \\
\hline Atropelamento & 44,64 \\
Colisáo de veiculos & 48,27 \\
Choque & 1,44 \\
Capotamento & 2,83 \\
Outros & 2,82 \\
\hline & \\
\hline \multirow{2}{*}{ Total } & 100,00 \\
\hline
\end{tabular}

No tocante à qualidade do falecido, evidenciou-se grande proporção de pedestres, que corresponde a $86,00 \%$ de todas as mortes; a seguir aparecem os motoristas de carros porém em proporção apreciavelmente menor, pois para cada morte de um destes, morreram aproximadamente 20 pedestres. Não se constatou nenhuma morte de motorista de ônibus.

T A B E L A 6

Mortes por Acidentes de transito de veiculo a motor segundo a qualidade do talecido - Sáo Paulo - 1970

\begin{tabular}{|c|c|c|}
\hline Qualidade & No & $\%$ \\
\hline Pedestre & 1211 & 86,00 \\
\hline Passagetro de carro & 53 & 3,76 \\
\hline Passageiro de onibus & 18 & 1,27 \\
\hline Passageiro de caminhso & 15 & 1,06 \\
\hline Motorista de carro & 66 & 4,68 \\
\hline Motorista de onibus & 一 & - \\
\hline Matorista de caminhüo & 13 & 0,92 \\
\hline Motociclista & 18 & $1 ; 27$ \\
\hline $\begin{array}{l}\text { Acompanhante de motoci- } \\
\text { clista }\end{array}$ & 2 & 0,14 \\
\hline Ciclista & 12 & 0,85 \\
\hline Total & 1408 & 100,00 \\
\hline Ignorado & 308 & \\
\hline TotaI & 1746 & \\
\hline
\end{tabular}

Para as 1746 mortes estudadas foi possível averiguar o local da residência em 1545 casos, dos quais $1328(85,95 \%)$ eram residentes na cidade de São Paulo e $217(14,05 \%)$ o eram em outros municípios. Para 201 casos não foi possível saber se a residência era ou não em São Paulo.

O conhecimento do número de mortes de residentes na área de estudo permitiu calcular o coeficiente de mortalidade por acidentes de veículo a motor. 
LAURENTI, $R$. et al, - Alguns aspectos epidemiologicos da mortalidade por acidentes de transito de veículo a motor na cidade de São Paulo, Brasll. Rev. Saúde públ., S. Paulo, 6: 329-41, 1972.

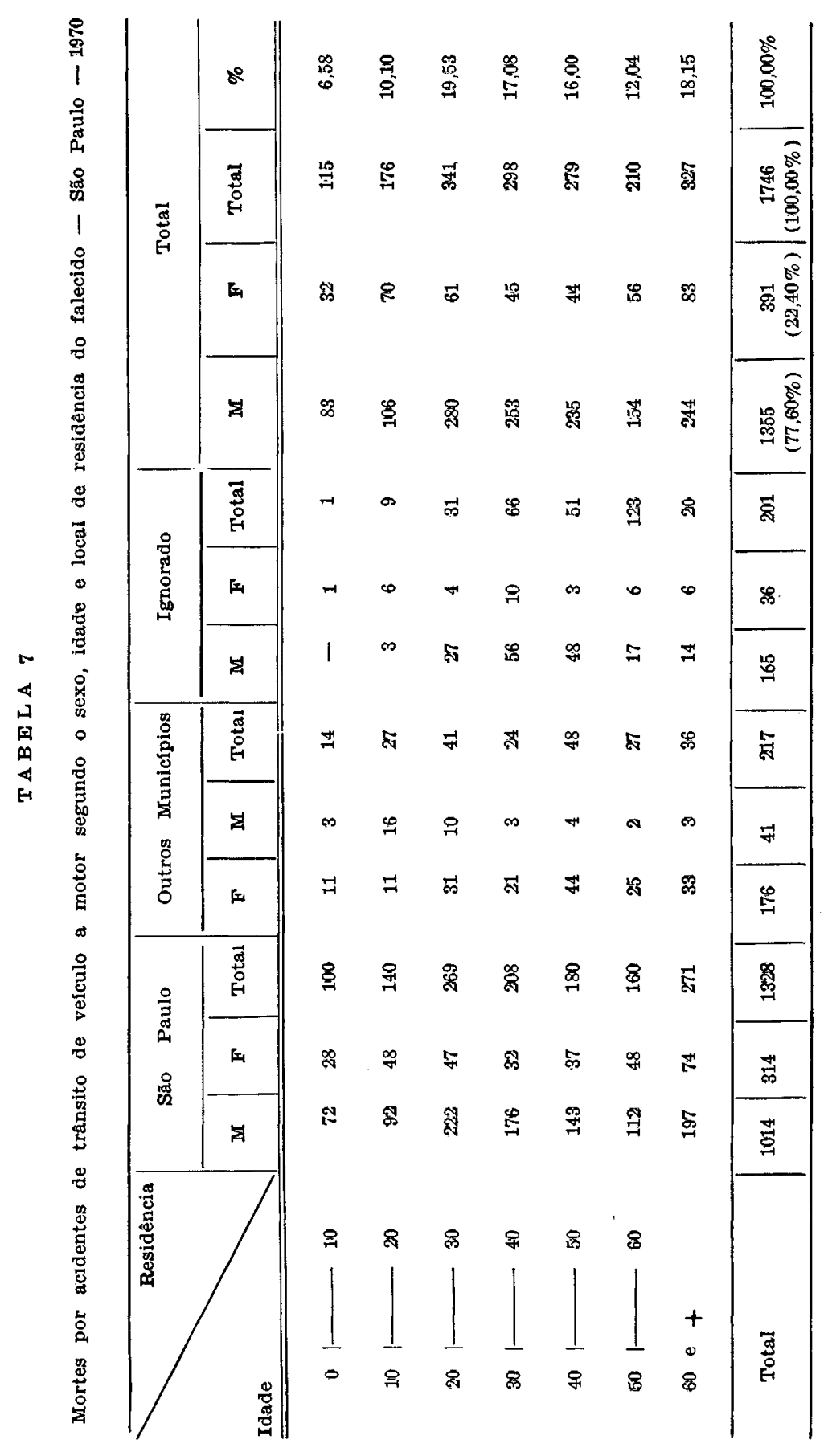


LAURENTI, R. et al. - Alguns aspectos epidemiologicos da mortalidade por acidentes de trânsito de veículo a motor na cidade de São Paulo, Brasil. Rev. Saúde pribl., S. Paulo, 6: 329-41, 1972.

Esse coeficiente é no mínimo 22,4/100.000 habitantes, relacionando-se os 1328 certamente residentes, e no máximo 25,8/ 100.000 habitantes se todos os 201 casos em que não se conseguiu saber 0 endereço fossem residentes em São Paulo. O coeficiente de mortalidade do sexo masculino foi aproximadamente 3,5 vezes maior do que o do sexo feminino, e em todos os grupos etários a mortalidade masculina foi maior. Em ambos os sexos, a mortalidade aumenta progressivamente, à medida que aumenta a idade, exceto para o grupo 30 a 40 anos. Os resultados reterentes à residencia dos falecidos, sexo e idade encontram-se na Tabela 7.

Na Tabela 8 estão expostos os resultados dos coeficientes de mortalidade por idade e sexo.

\section{TABILA 8}

Mortalidade por acidente de transito de veiculo a motor segundo sexu e idade - Coeficientes $x$ 100.000 habs. - Săo Paulo - 1970

\begin{tabular}{|c|c|c|}
\hline$X_{i}$ Sexo & $\mathbf{M}$ & $\mathbf{F}$ \\
\hline $0 \quad-10$ & 10,3 & 4,1 \\
\hline $101-20$ & 15,0 & 7,3 \\
\hline $201-30$ & 42,6 & 8,6 \\
\hline $30 \quad-{ }^{4}{ }^{4}$ & 39,3 & 6,7 \\
\hline $401-50$ & 48,3 & 12,3 \\
\hline $501-60$ & 58,3 & 24,5 \\
\hline 60 e + & 138,8 & 44,4 \\
\hline Total & 34,7 & 10,5 \\
\hline
\end{tabular}

TAB E L A 9

Mortes por acidentes de veículo a motor segundo a ldade e o local do b́bito

\begin{tabular}{|c|c|c|c|c|}
\hline $7^{\text {local }}$ & Hospital & $\begin{array}{c}\text { Caminho do } \\
\text { Hospital }\end{array}$ & $\begin{array}{l}\text { Local do } \\
\text { acidente }\end{array}$ & TOTAL \\
\hline idade & & & pestis & \\
\hline $01-10$ & 69 & 36 & 10 & 115 \\
\hline $10 \longmapsto 20$ & 122 & 36 & 18 & 176 \\
\hline $201-30$ & 212 & 111 & 18 & 341 \\
\hline $301-40$ & 177 & 89 & 39 & 298 \\
\hline $40 门 50$ & 184 & 66 & 29 & 279 \\
\hline $50 \quad-60$ & 145 & 46 & 19 & 210 \\
\hline $60 \mathrm{e}+$ & 233 & 70 & 24 & 317 \\
\hline Total & $\begin{array}{c}1142 \\
(65,4 \pm \%)\end{array}$ & $\begin{array}{c}454 \\
(26,00 \%)\end{array}$ & $\begin{array}{c}150 \\
(8,59 \%)\end{array}$ & $\begin{array}{c}1746 \\
(100,00 \%)\end{array}$ \\
\hline
\end{tabular}

Quanto ao fato de o falecido ter ou não sido hospitalizado após o acidente, isso foi verificado pelo local onde ocorreu o óbito, não tendo sido medido o tempo médio de hospitalização. Verificou-se que $65,41 \%$ foram hospitalizados, $8,59 \%$ faleceram no próprio local do acidente e os restantes $26,00 \%$ faleceram em trânsito para o hospital (Tabela 9).

\section{COMENTARIOS}

A mortalidade por acidentes de trânsito de vef́culo a motor na cidade de São Paulo, medida pelo coeficiente de mortalidade, tal como está apresentada na Tabela 1 foi sempre superestimada, dado que não é feita a correção para a residência do falecido. O Instituto Médico Legal realiza as necrópsias de todos 
LAURENTI, $R$, et al. - Alguns aspectos epidemiológicos da mortalidade por acidentes de transito de veículo a motor na cidade de são Paulo, Brasil. Rev. Saúde públ., S. Paulo, 6: $329-41,1972$.

os casos de óbito por acidentes ocorridos na cidade de São Paulo (residentes ou não) e também aqueles ocorridos em alguns municípios vizinhos, como Taboão, Embu, Cotia, Guarulhos e outros. Como esses óbitos são registrados na Capital, são computados para o cálculo da mortalidade dessa área. Assim, em 1970 foram realizadas 1883 necrópsias de óbitos por esse tipo de acidente, o que dá um coeficiente de $31,7 \times 100.000$ habitantes. Ocorre porém, como se viu na Tabela 7 , que os residentes foram somente 1328 ou no máximo 1328 mais 201 se se admitir que todos os de domicílio ignorado fossem residentes. Dessa maneira, teríamos uma mortalidade real de no mínimo 22,4 e no máximo 25,8/100.000 habitantes em 1970, relacionando-se à população residente na área (5.921.796, dado do Censo). Mesmo com essa correção, a mortalidade por essa causa é bastante alta, o que é um fato interessante, pois, se por um lado isso pode ser comparável aos padrões de mortalidade que se observam em áreas desenvolvidas, por outro temos ainda problemas comuns às áreas menos desenvolvidas, como por exemplo a alta mortalidade infantil e mesmo a mortalidade por algumas doenças in. fecciosas.

Quanto às regióes da cidade de maior ocorrência de acidentes fatais, destaca-se a zona Sul com $32,86 \%$ das mortes observadas. Nessa região está situada a área do distrito policial onde se verificou a maior proporção de mortes que foi a Cidade Ademar, e nesta destacaram-se como vias de maior número de acidentes a Av. Interlagos, Av. Cupecê e a Estrada de Parelheiros.

As zonas Norte e Oeste foram onde se verificou menor número, porém nesta última, no bairro de Vila Mangalot, observou-se grande número de mortes. As ocorrências aí foram registradas em grande parte na Via Anhanguera e também na Rodovia Castelo Branco. Na
Zona Oeste, também a Lapa aparece com número significativo de mortes, possivelmente relacionado às vias de saída rumo às rodovias acima citadas.

Na Zona Leste, destaca-se o distrito policial de São Miguel Paulista onde ocorreram $5,73 \%$ de todas as mortes por acidentes de veículo a motor ocorridos no município, número somente inferior ao verificado na Cidade Ademar $(6,12 \%)$.

Uma análise detalhada de ruas, avenidas, cruzamentos e estradas, onde ocorreram os acidentes que produziram mortes, não foi possível, pois essa especificação nem sempre existia, principalmente nos casos de vítimas que permaneceram algum tempo internadas em hospitais. A especificação para a área da ocorrência correspondente ao distrito policial não foi conseguida em 456 casos. Porém, a distribuição para os $1290 \mathrm{em}$ que isso foi possível dá uma boa idéia das áreas ou zonas de maior ocorrência de acidentes fatais. As Avenidas ou ruas Ruben Berta, 23 de Maio, Radial Leste, Estrada S. Miguel Paulista, Marginais Tietê e Pinheiros, Interlagos, do Estado, Rangel Pestana, São João, aparecem frequientemente como locais de acidentes mortais. Um aspecto importante que deverá ser levado em conta em um estudo desse tipo é a localização dos pontos preferenciais dos acidentes, mortais ou não, pois essas informações trazem valiosa contribuição quando se pensa em prevenção. Entre nós, entretanto, um estudo desse tipo só poderá ser feito com os dados contidos nos "Boletins de Ocorrência".

Quanto à distribuição mensal dos óbitos, os meses de maio, agosto e dezembro foram aqueles com maior número; fevereiro apresentou o menor número de óbitos, mesmo fazendo-se a correção para 30 dias. Este mês foi também o que apresentou o menor número de acidentes registrados e também de vitimas, o que se deve, possivelmente, 
LAURENTI, R. et al. - Alguns aspectos epidemiológicos da mortalidade por acidentes de trânsito de veículo a motor na cidade de São Paulo, Brasıl. Rev. Saúde públ., S. Paulo, 6: $329-41,1972$.

ao fato de constituir período de férias, ocasiāo em que o número de pessoas que sai de São Paulo é muito grande. Em janeiro, que também é mês de férias, foi observado maior número de acidentes, porém o número de mortes foi inferior à média mensal.

Relacionando-se os acidentes, as vítimas e os óbitos podem ser medidos determinados riscos: assim, o risco de ser vitimado em um acidente de trânsito é em média 62,50\%, ou seja, cada 100 acidentes ocasionam, no ano, 62,5 vítimas. Por outro lado, para cada 100 acidentes, em média, ocorrem 5,13 mortes e cada 100 vítimas resultam, em média, 8,22 mortes. Verificou-se que no mês de julho os acidentes provocaram um número de vítimas pouco inferior à média mensal, vítimas essas que provocaram um número de mortes superior a média mensal, sendo que o risco da vitima falecer foi o maior observado nos $12 \mathrm{me}$ ses. Julho seria então o mês de maior gravidade dos acidentes.

Em relação a fevereiro, que foi como se disse o mês com menor número de acidentes, de vítimas e de mortes, verificou-se um maior risco, entre todos os meses, de um acidente produzir vítimas $(63,89 \%)$. Porém, um dos menores ris$\cos$ do acidente ocasionar mortes $(4,63 \%)$ e do vitimado vir a falecer $(7,40 \%)$.

No tocante aos dias da semana, a maior proporção de mortes ocorre aos sábados e domingos, fato aliás já evidenciado em alguns trabalhos 3,5 . De uma maneira geral, pode-se dizer que o maior número de mortes registradas nos fins de semana, em outros países, está relacionado aos acidentes ocorridos em estradas, devido ao grande movimento.

Pode-se considerar que os fins de semana são relativamente calmos quanto ao trânsito, em relação aos outros dias e o que poderia estar ocorrendo são também acidentes de estradas naquelas áreas do município atravessadas por estradas, como são os inícios das Vias Dutra, Anhanguera, Castelo Branco, Raposo Tavares, Anchieta, Fernão Dias, Regis Bittencourt e outras menos importantes.

Quanto à qualidade do falecido, $86,00 \%$ foram pedestres e os restantes 14,00\%: passageiros de carro, ônibus e caminhão, motoristas de carro e caminhão, motociclistas e acompanhantes e ciclistas. $O$ fato de a maioria das mortes ter sido de pedestres parece indicar a grande falta de segurança que as vias públicas oferecem aos mesmos. Medidas deveriam ser adotadas no sentido de uma melhor sinalização, faixas de segurança, e principalmente, a nosso ver, educação no sentido de obediência a essas medidas, quer por parte dos pedestres, quer por parte dos motoristas, o que, ousamos dizer, em São Paulo é praticamente inexistente!

Quanto à mortalidade por idade e sexo observou-se que o coeficiente para 0 sexo masculino é aproximadamente $\mathbf{3 , 5}$ vezes maior comparado ao sexo feminino. Para todos os grupos etários considerados, a mortalidade foi bem maior no sexo masculino chegando, por exemplo, no grupo etário 20 a 30 anos ser aproximadamente 5 vezes maior.

Essa pređominância observada no sexo masculino poderia ser explicada pela maior exposição ao risco, pois os homens se locomovem mais na cidade, principalmente pela mobilização no trabalho. A maior mortalidade no sexo masculino tem sido verificada também em outras áreas ${ }^{2}, 3,6$.

A mortalidade por acidentes de veículo a motor específica para grupos etários evidenciou um aumento com a idade, chegando no grupo acima de 60 anos a 138,8 e $44,4 / 100.000$ habitantes, respectivamente nos sexos masculino e feminino. Tendo-se em vista que $86,00 \%$ dos mortos foram pedestres, poder-se-ia atri- 
LAURENTI, $R$. et al. - Alguns aspectos epidemiológicos da mortalidade por acidentes de trânsito de vef́culo a motor na cídade de são Paulo, Brasil. Rev. Saúde públ., S. Paulo, 6: $329-41,1972$.

buir isso ao fato de as pessoas mais idosas serem aquelas menos ágeis nas "corridas" ao atravessar as vias puiblicas, muitas vezes transformadas em verdadeiras pistas. Já em 1962/63, um estudo realizado em São Paulo 8 evidenciava a maior mortalidade nas idades de 55 a 64 e 65 a 74 anos, em ambos os sexos; neste mesmo estudo foi comparada a mortalidade verificada em dez cidades latino-americanas, incluindo São Paulo, e duas cidades de língua inglesa (Bristol na Inglaterra e S. Francisco na California).. No grupo etário, mais jovem - 15 a 24 anos - os pedestres representavam apenas $4,00 \%$ dos óbitos em Bristol e São Francisco e $70,00 \%$ nas cidades latino-americanas. No grupo etário mais velho compreendido no estudo 65 a 74 anos - estas proporções foram respectivamente $86,00 \%$ e $92,00 \%$. Os óbitos nas cidades latino-americanas, mesmo nas idades jovens, apresentaram maior proporção de pedestres, proporção esta que aumentava nas idades mais velhas. Também nas duas cidades de língua inglesa, seguramente com maior tradição automobilística, nos grupos etários mais avançados, a grande maioria dos falecidos nos acidentes foi de pedestres e não de passageiros, motoristas ou outros.

De todos Os óbitos ocorridos em São Paulo, 65,41\% tiveram atendimento hospitalar. Não foi pesquisado o tempo de internação, porém, uma análise deste tipo seria bastante interessante, pensando-se em termos de disponibilidade de leitos, permanência média e outros recursos hospitalares, além dos gastos que isso representa. O número dos que receberam atendimento hospitalar foi 1142, considerando-se apenas os que faleceram, porém muitos daqueles feridos em acidentes também tiveram hospitalização. Dessa maneira, se dos 21.235 feridos registrados em $1970,50 \%$ tivessem sido internados, pode-se fazer uma idéia do que isso representaria em termos de demanda hospitalar. Nos Estados Unidos, cerca de duas mil pessoas são hospitalizadas por ano devido a todos os tipos de acidentes, dos quais $15 \%$ são por veículos a motor 4 .

As informaçōes do DETRAN referem que em 1970 havia no município de São Paulo 520.981 veículos licenciados. $O$ cálculo de uma taxa de acidentes, de feridos e de mortos relacionado com o número de veículos licenciados supra citado parece totalmente fora de propósito, pois o número de veículos procedentes de outros municípios e que causam também acidentes, feridos e mortes é muito grande e esse número é impossível de ser conhecido. Assim, o DETRAN calculou para 1970, no município de São Paulo, para cada dez mil veículos existentes: 652 acidentes, 244 acidentes somente com danos, 371 feridos e 36 mortos. Estes cálculos, porém, levam em consideração somente os veículos lìenciados no município não sendo feita correções para veículos de fora. Seria muito interessante uma análise deste ponto de vista, pois pode-se imaginar a proporção apreciável de acidentes causados por veículos não pertencentes ao município. Pensando-se em prevenção de acidentes, este é um aspecto que deve ser considerado.

Este trabalho teve por finalidade salientar alguns aspectos da mortalidade por acidentes de veículo a motor na cidade de São Paulo, chamando a atenção para a gravidade do problema. Não foi possivel uma análise mais minuciosa visto não se dispor de todas as informações necessárias; além do mais, um estudo epidemiológico sobre o assunto, para ser completo, deveria abranger todos os acidentes, mortais ou não. Todavia, os aspectos que foram aqui descritos para os acidentes mortais refletem o que ocorreu com todos os acidentes de veículo a motor, qualquer que tenha sido o dano causado. 
LAURENTI, R, et al. - Alguns aspectos epidemiológicos da mortalidade por acidentes de transito de velculo a motor na cidade de sao Paulo, Brasll. Rev. Saúde públ., S. Paulo, 6: 329-41, 1972 .

\section{CON CLUSO ES}

A mortalidade por acidentes de trânsito de veículo a motor no Município de São Paulo no ano de 1970:

1) foi alta, mesmo fazendo-se a correção considerando-se somente os residentes;

2) a zona onde ocorreu o maior número de mortos foi a Sul $(32,86 \%$ dos casos); em todas as zonas observaram-se algumas áreas (distritos policiais) com maior número de casos, destacando-se nas áreas algumas vias públicas;

3) observou-se que, em média, cada 100 acidentes ocasionaram 62,50 vítimas e 5,13 mortes e para cada 100 vítimas ocorreram 8,22 mortes;

4) alguns meses destacaram-se pela maior frequiência de acidentes, de vítimas ou de mortes. Aos sábados e domingos o número de mortes é maior;

5) os pedestres representaram $86 \%$ dos mortos;

6) o coeficiente de mortalidade do sexo masculino é aproximadamente 3,5 vezes maior que no sexo feminino; em ambos os sexos aumenta com a idade, sendo maior acima dos 60 anos;

7) $65,41 \%$ dos falecidos receberam atendimento hospitalar apos o acidente.

RSPSP-147

LAURENTI, R. et al, - [Mortality by motor vehicles traffic accidents in the city of. S. Paulo, Brazil: some epidemiological aspects]. Rev. Saúde públ., S. Paulo, 6:329-41, 1972.

SUMmary: With data taken from the post-mortem records of the Office of the Medical Legal Examiner, the authors have studied some characteristics of death in motor vehicles traffic accidents in the city of São Paulo, Brazil during the period of January 1 till December 31, 1970. The study shows that there is a high mortality; it varies with sex and age, being higher among males and with the highest rates among those over 60's. Traffic accidents generally occur in the major thoroughfares but its in- cidence is higher in the South part of the city and mainly on Saturdays and Sundays. A reasonable proportion of the deceaseds mainly pedestrians, was attended at a hospital. The total number of accidents, victims and deaths showing that for each 100 accidents there were 62,50 victims and 5,13 deaths and for each 100 victims, 8,22 deaths.

UNITERMs: Accidents, Traffic*; Vehicles, motor *; Mortality *, Automobile driving; Epidemiology.

\section{AGRADECIMENTOS}

Ao Dr. Arnaldo Siqueira, diretor do Instituto Médico Legal, pelas facilidades concedidas para consulta dos laudos de necrópsia.

\section{REFERANCIAS BIBLIOGRAFICAS}

1. DEMOGRAPHIC YEARBOOK, 1969. N. York, United Nations, 1970.

2. DONALD, F. H. \& GIKAS, P. W. - Cau. ses of deaths in automobile accidents. J. Amer. med. A88., 203:7, 1963.

3. FAVHRO, M. - Estudo epidemiolbgico dos acidentes de transito $\mathrm{cm}$ Ribeirio Preto. Ribeirăo Preto, 1971. [Tese de doutoramento - Faculdade de Medicina de Ribeiråo Preto].

4. ISKRANT, A. P. \& JOLIET, P. V. Acoidents and homicide. Cambridge, Harvard University Press, 1968.

5. MAC CARROL, J. R. \& HADON, W. J. - A controlled study of fatal automo. bile accidents in New York city. $J$. chron. Dis., 15: 811.26, 1962.

6. MARKUSH, R. E. et al. - Motor vehicle accidents in United States (1906-1964). J. Amer. med. Ass., 203:1105, 1968.

7. NORMAN, I. G. - Road traffic accidents epidemiology, control and prevention. Geneva, World Health Organization, 1962. (Public Health Papers, 12).

8. PUFFFR, R. R. \& GRIFFTH, W. G. Canacteristicas de la mortalidad urba na: informe de la Investigacion Inter. americana de la Mortalidad. Washing. ton, D.C., Organizacion Panamertcana de la Salud, 1968. [Publicacion cienti. flc, 157.]

9. SINNETTE, C. H. - Los accidentes en la niñez en el Suroeste de Nigeria. Bol. Ofic. Banit. panamer., 49: 8-19, 1970.

Recebido para publisagdo em 2-10-1971 Aprovado para publicacdo em 25-10-1972 